Research Article

\title{
Experimental and Modeling Studies of Stress Wave Propagation and Energy Dissipation Mechanism in Layered Composite Structures
}

\author{
Youchun Zou, Chao Xiong ${ }^{D}$, Junhui Yin $\mathbb{D}^{D}$, Huiyong Deng, Kaibo Cui, and Sa Zhang \\ Department of Artillery Engineering, Army Engineering University of PLA, Shijiazhuang 050003, China \\ Correspondence should be addressed to Chao Xiong; ljgcdxxiongchao@163.com and Junhui Yin; yuanzhidao@163.com
}

Received 24 March 2021; Accepted 13 July 2021; Published 28 July 2021

Academic Editor: R. Luo

Copyright ( 2021 Youchun Zou et al. This is an open access article distributed under the Creative Commons Attribution License, which permits unrestricted use, distribution, and reproduction in any medium, provided the original work is properly cited.

\begin{abstract}
Four composite structures (SiC/UHMWPE/TC4, SiC/TC4/UHMWPE, SiC/UHMWPE/MR/TC4, and SiC/TC4/MR/UHMWPE) were prepared using silicon carbide ( $\mathrm{SiC}$ ) ceramics, ultrahigh molecular weight polyethylene (UHMWPE), titanium alloy (TC4), and metal rubber (MR). The transmitted waves, failure forms, stress wave propagations, and energy dissipations of the composite structures were studied through Split Hopkinson Pressure Bar (SHPB) tests and numerical simulations. The results show that MR in composite structures can delay, attenuate, and smooth the stress wave, thereby reducing SiC damage. UHMWPE on the back of $\mathrm{SiC}$ provides cushioning for $\mathrm{SiC}$, while $\mathrm{TC} 4$ on the back of $\mathrm{SiC}$ aggravates the damage of $\mathrm{SiC}$. The composite structures with $\mathrm{MR}$ mainly dissipate the impact energy by reflecting energy, and the energy dissipation performance is better than that of composite structures without MR. A comprehensive comparison of transmitted waves, damage forms, stress wave propagations, and energy dissipations of the four composite structures shows that SiC/UHMWPE/MR/TC4 structure has the best impact resistance. Increasing the thickness of MR in the composite structures can improve the impact resistance, but there are also stress concentration and interface tensile stress.
\end{abstract}

\section{Introduction}

The layered composite structure is composed of two or more materials with different mechanical properties. Studies have shown that the layered composite structure is lighter in weight, better in impact resistance, and more designable than homogeneous materials $[1,2]$. Layered composite structures have been widely used in military and civilian fields [3], such as armored vehicle [4], helicopter [5], ship [6], body armor [7], helmet [8], vehicle bumper [9], and highway guardrail [10].

In recent years, porous metal materials such as aluminum foams have been widely used in impact-resistant structures due to good energy absorption properties. Rajaneesh et al. [11] used LSDYNA software to study the mechanical behavior of aluminum foam composite structures under low-velocity impact. The results show that the energy absorbed by the composite structure depends on the type of panel and the thickness of the aluminum foam, and the peak load is only related to the type of panel. Liu et al. [12] studied the shock wave attenuation performance and deformation mechanism of aluminum foam composite structures under explosive loading. It is found that the peak load of the foam composite structure is reduced by $61.54 \%$ $64.69 \%$ compared with the structure without foam core, and the foam core layer dissipates energy mainly through the generation and propagation of cracks. Avila et al. [13] investigated the ballistic limit of the layered composite structure of boron carbide ceramic/foam metal/7075 aluminum through projectile penetration experiments. It is found that the metal foam effectively reduces the penetration depth and backplane deformation of the composite structure, and the metal foam composite structure has excellent antipenetration performance. Cai et al. [14] conducted an experimental study on the failure mechanism of aluminum foam/ultrahigh molecular weight polyethylene composite 
structure under the combined loading of explosion and fragments. The results show that the aluminum foam in the composite structure can be beneficial to improve the comprehensive protection ability.

In order to develop the composite structure with stronger impact resistance, new materials need to be applied. Metal rubber (MR) is a porous metal material, and its higher porosity helps to absorb shock wave energy [15]. The research studies of MR mainly focus on stiffness characteristics [16], damping characteristics [17], and fatigue life [18] and rarely involve the research studies of the dynamic shock response. Gao et al. [19] found that the penetration resistance of the MR composite structure is better than that of the aluminum foam composite structure, but the mechanism has not been studied in depth.

To give full play to the impact resistance of the layered composite structure, it is necessary to apply the dynamic mechanics theory of materials to guide engineering practice. The dynamic response of a solid under impact load is essentially the inertia effect of the solid mass point and the strain rate effect of the material constitutive relationship, and the impact compression performance of the material can usually be analyzed by the stress wave propagation characteristics [20, 21]. However, the current research studies on the dynamic mechanical properties of layered composite structures mostly focus on the evaluation of penetration and damage effects and rarely involve stress wave propagation characteristics.

At present, there are few studies on the stress wave propagation characteristics of layered composite structures, and $\mathrm{MR}$ is rarely used in the field of impact resistance.

Four composite structures (SiC/UHMWPE/TC4, SiC/ TC4/UHMWPE, SiC/UHMWPE/MR/TC4, and SiC/TC4/ $\mathrm{MR} / \mathrm{UHMWPE}$ ) were designed using silicon carbide ( $\mathrm{SiC})$ ceramics, ultrahigh molecular weight polyethylene (UHMWPE), titanium alloy (TC4), and metal rubber (MR). Through Split Hopkinson Pressure Bar (SHPB) tests and numerical simulations, the stress wave propagation characteristics and energy dissipation performance of the designed composite structures were mainly studied. The main research contents are as follows. Firstly, the simulation models were established, and the correctness was verified by experiments. Secondly, the transmitted waves, failure forms, stress wave propagations, and energy dissipations of the composite structures were investigated through SHPB experiments and numerical simulations. Through the comparison of the results, the influences of material arrangement and MR on the dynamic mechanical behavior of the composite structures were analyzed. Finally, the influences of the MR thickness on the stress wave propagation and energy dissipation of the composite structures were discussed.

\section{Materials and Methods}

2.1. Materials. The materials for preparing the composite structures include silicon carbide ( $\mathrm{SiC}$ ) ceramics, titanium alloys (TC4), ultrahigh molecular weight polyethylene (UHMWPE) laminates, and metal rubber (MR). SiC has high hardness, but the material is brittle and the tensile strength is low. TC4 has high strength and ductility, but high density limits its application. UHMWPE laminates has high tensile strength and light weight and is widely used in lightweight protective structures. MR has good energy absorption and damping characteristics. The UHMWPE laminate is made of unidirectional fiber coated with polyurethane through hot pressing process, and the lay angle is $\left[0^{\circ} / 90^{\circ} / 0^{\circ} / 90^{\circ}\right]$. MR has a density of $2.38 \mathrm{~g} / \mathrm{cm}^{3}$ and is stamped from austenitic stainless-steel wire $(0 \mathrm{Cr} 10 \mathrm{Ni})$ with a diameter of $0.3 \mathrm{~mm}$. The four materials were processed into cylinders with a diameter of $40 \mathrm{~mm}$, and the thickness of SiC, TC4, UHMWPE, and MR is $5 \mathrm{~mm}, 6 \mathrm{~mm}$, $5 \mathrm{~mm}$, and $10 \mathrm{~mm}$, respectively. A small amount of petroleum jelly was smeared on the edge of the circular section of the material to connect the materials, which can also avoid the interference of the petroleum jelly on the propagation of the stress wave.

As shown in Figure 1, four composite structures were designed based on the above materials, which can better compensate for the shortcomings of each material. $\mathrm{SiC}$ has high hardness and is usually used as panel to consume most of the impact energy. Through the comparison of four composite structures, the influences of material arrangement and MR on the dynamic mechanical properties of composite structures were studied.

\subsection{Methods}

2.2.1. Split Hopkinson Pressure Bar (SHPB) Test. As shown in Figure 2, the high-speed impact tests were performed on the SHPB equipment. The bars are made of 7075 aluminum alloy with a diameter of $45 \mathrm{~mm}$. The lengths of the striker, incident bar, and transmitted bar are $400 \mathrm{~mm}, 2500 \mathrm{~mm}$, and $2500 \mathrm{~mm}$, respectively. The high-speed camera was used to capture the entire impact process. The velocity of the striker in each experiment was $30 \mathrm{~m} / \mathrm{s}$. In order to ensure the accuracy of the test results, each structure was tested 3 times and the average of the results was taken.

2.2.2. Finite Element Model. The finite element analysis was performed in LSDYNA software. The 8-node solid164 element was used to establish the model. The entire model only has a degree of freedom, namely, axial direction. The geometric parameters of the finite element model are consistent with the test conditions. The SHPB system, SiC, UHMWPE, TC4, and MR were, respectively, meshed into 5888, 2304, 2304, 2304, and 4608 elements. Each part of the system was connected with ${ }^{*}$ CONTACT_AUTOMATIC_SURFACE_TO_SURFACE. The isotropic linear elastic material model *MAT_ELASTIC_TITLE was used to define the bars, with the elastic modulus of $71 \mathrm{GPa}$ and density of $2.81 \mathrm{~g} / \mathrm{cm}^{3}$. The model parameters of SiC, TC4, UHMWPE, and MR are shown in Tables 1-4. The JOHNSON_HOLMQUIST_CERAMICS model is widely used in brittle materials that withstand large strains, large strain rates, and high pressures, which can reflect the fracture of ceramics. The Johnson-Cook model is applied to metal materials affected by large strain, high strain rate, and high temperature and can 

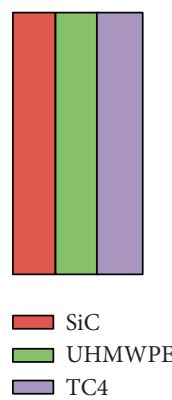

(a)
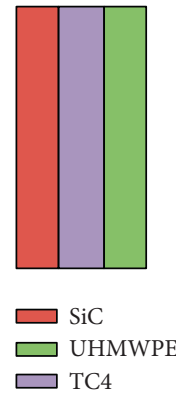

(b)
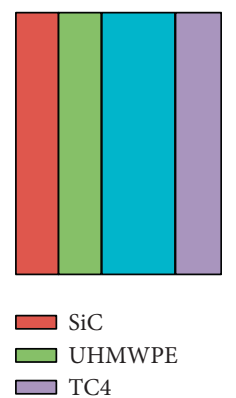

$\square \mathrm{TC} 4$
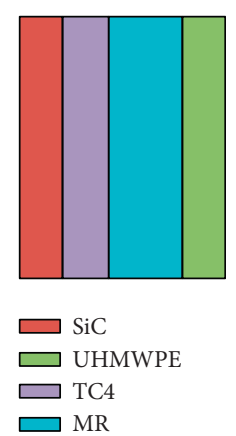

(d)

Figure 1: Four types of composite structure (a) SiC/UHMWPE/TC4; (b) SiC/TC4/UHMWPE; (c) SiC/UHMWPE/MR/TC4; (d) SiC/TC4/ MR/UHMWPE.

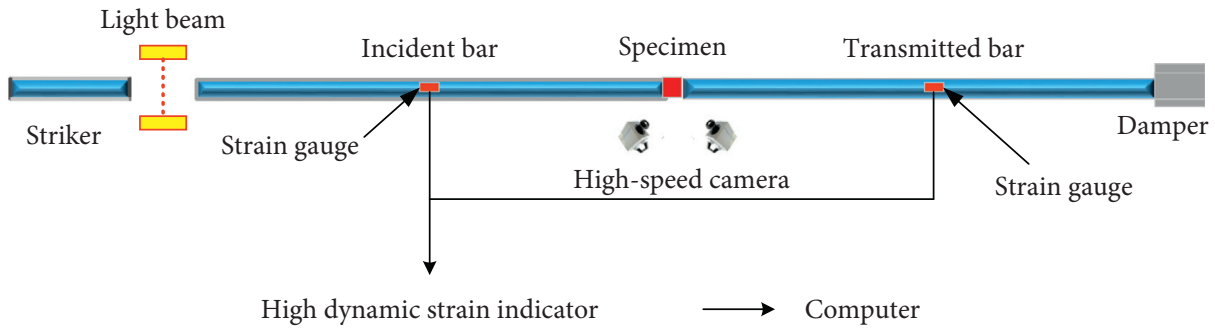

Figure 2: The SHPB test system.

TABle 1: *MAT_JOHNSON_HOLMQUIST_CERAMICS [22] constants for SiC.

\begin{tabular}{lc}
\hline Constants & $\mathrm{SiC}$ \\
\hline Density $\left(\mathrm{g} / \mathrm{cm}^{3}\right)$ & 3.2 \\
Shear modulus, $G(\mathrm{GPa})$ & 183 \\
Intact strength coefficient, $A$ & 0.96 \\
Fracture strength coefficient, $B$ & 0.35 \\
Strain rate coefficient, $C$ & 0.0045 \\
Intact strength exponent, $N$ & 0.65 \\
Fracture strength exponent, $M$ & 1.0 \\
Maximum tensile pressure strength, $T(\mathrm{GPa})$ & 0.75 \\
Pressure at HEL, PHEL $(\mathrm{GPa})$ & 14.567 \\
Damage coefficient, $D_{1}$ & 0.48 \\
Damage exponent, $D_{2}$ & 0.48 \\
Bulk modulus, $K_{1}(\mathrm{GPa})$ & 217.2 \\
Pressure coefficient, $K_{2}(\mathrm{GPa})$ & 0 \\
Pressure coefficient, $K_{3}(\mathrm{GPa})$ & 0 \\
\hline
\end{tabular}

be used to reflect the dynamic response state of TC4. The COMPOSITE_DAMAGE model is suitable for solving the dynamic response of UHMWPE. During the impact of the bar on the composite structure, the dynamic mechanical response of MR was similar to that of rubber and * MAT_HYPERELASTIC_RUBBER was used to define MR. As shown in Table 4, through the previous research, the parameters of MR were fitted in the ${ }^{*}$ MAT_HYPERELASTIC_RUBBER constitutive model. The comparison of experimental and simulation results showed that the established constitutive model can accurately reflect the dynamic mechanical behavior of MR under high-speed impact.
TABle 2: *MAT_JOHNSON_COOK [22] constants for TC4.

\begin{tabular}{lc}
\hline Constants & TC4 \\
\hline Density $\left(\mathrm{g} / \mathrm{cm}^{3}\right)$ & 4.45 \\
Shear modulus, $G(\mathrm{GPa})$ & 41.9 \\
Static yield strength, $A(\mathrm{GPa})$ & 1.0 \\
Strain hardening coefficient, $B(\mathrm{GPa})$ & 0.845 \\
Strain hardening exponent, $n$ & 0.58 \\
Strain rate coefficient, $C$ & 0.014 \\
Reference strain rate, $\left(\mathrm{s}^{-1}\right)$ & 1.0 \\
Thermal softening exponent, $m$ & 0.753 \\
Reference temperature, $t_{0}(\mathrm{~K})$ & 298 \\
Melting temperature, $t_{m}(\mathrm{~K})$ & 1951 \\
Damage constant, $D_{1}$ & 0.05 \\
Damage constant, $D_{2}$ & 0.27 \\
Damage constant, $D_{3}$ & -0.48 \\
Damage constant, $D_{4}$ & 0.014 \\
Damage constant, $D_{5}$ & 3.8 \\
\hline
\end{tabular}

\section{Results and Discussion}

3.1. Comparison of Experimental and Simulated Results. As shown in Figure 3, the experimental results and the numerical simulation results are in good agreement, and the established finite element model can reliably simulate the dynamic mechanical response of the composite structures. In composite structures III and IV, the transmitted waves rise slowly, and the amplitude and wavelength of the transmitted waves are small. The above phenomena show that MR can delay the elastic compression waves and effectively attenuate the energy of the transmitted waves. In addition, the transmitted waves of the composite structures 
TABlE 3: *MAT_COMPOSITE_DAMAGE [23] constants for UHMWPE.

\begin{tabular}{lc}
\hline Constants & UHMWPE \\
\hline Density $\left(\mathrm{g} / \mathrm{cm}^{3}\right)$ & 0.97 \\
Young's modulus in $a$-direction, $E_{a}(\mathrm{GPa})$ & 30.7 \\
Young's modulus in $b$-direction, $E_{b}(\mathrm{GPa})$ & 30.7 \\
Young's modulus in $c$-direction, $E_{c}(\mathrm{GPa})$ & 1.97 \\
Poisson's ratio, $b a v_{b a}(\mathrm{GPa})$ & 0.008 \\
Poisson's ratio, $c a v_{c a}(\mathrm{GPa})$ & 0.044 \\
Poisson's ratio, $c b v_{c b}(\mathrm{GPa})$ & 0.044 \\
Shear modulus, $a b G_{a b}(\mathrm{GPa})$ & 0.73 \\
Shear modulus, $b c G_{b c}(\mathrm{GPa})$ & 0.67 \\
Shear modulus, $c a G_{c a}(\mathrm{GPa})$ & 0.67 \\
Bulk modulus of failed material, $K_{\text {fail }}(\mathrm{GPa})$ & 2.2 \\
AOPT & 0 \\
Material axes change flag for brick elements, $\mathrm{MACF}$ & 1 \\
Shear strength, $S_{c}(\mathrm{GPa})$ & 0.36 \\
Longitudinal tensile strength, $a$-axis, $X_{t}(\mathrm{GPa})$ & 3.0 \\
Transverse tensile strength, $b$-axis, $Y_{t}(\mathrm{GPa})$ & 3.0 \\
Transverse compressive strength, $b$-axis, $Y_{c}(\mathrm{GPa})$ & 2.2 \\
Shear stress parameter for the nonlinear term, $\alpha$ & 0.5 \\
Normal tensile strength, $S_{n}(\mathrm{GPa})$ & 0.95 \\
Tranverse shear strength, $S_{y z}(\mathrm{GPa})$ & 0.95 \\
Tranverse shear strength, $S_{x z}(\mathrm{GPa})$ & 0.95 \\
\hline
\end{tabular}

TABle 4: *MAT_HYPERELASTIC_RUBBER for MR.

\begin{tabular}{lc}
\hline Constants & $\mathrm{MR}$ \\
\hline Density $\left(\mathrm{g} / \mathrm{cm}^{3}\right)$ & 2.38 \\
Poisson's ratio, $P R$ & 0.4999 \\
Number of constants to solve for $N$ & 0 \\
$C_{10}$ & 141 \\
$C_{20}$ & 584 \\
$C_{11}$ & -607 \\
$C_{01}$ & -135 \\
$C_{02}$ & 168 \\
\hline
\end{tabular}

I, II or III, IV are different, indicating that the arrangement of materials also affects the stress wave dissipation performance of the composite structures.

As shown in Figure 4, in order to prove the reliability of the numerical simulation, the composite structure III was taken as an example to discuss the influence of the mesh size on the numerical simulation results. In Figure 4, the base mesh represents the mesh described in section 2.2.2, and the reduction of mesh size by two or three times means that the size of the base mesh is reduced by two or three times in both axial and circumferential directions to make the mesh denser. As shown in Figure 4, the relative errors of the numerical simulation results of the three meshes are relatively small, which proves that the numerical simulation results are convergent. Therefore, using the base mesh can not only provide accurate results but also reduce calculation time.

3.2. Analysis of Damage Form. Figure 5 shows high-speed photographs and corresponding stress diagrams of composite structure I. The impact directions of all high-speed photographs and stress diagrams in the paper are shown in
Figure 5(a), and the first to be impacted is $\mathrm{SiC}$. As shown in Figure $5, \mathrm{SiC}$ begins to fail when the stress wave reaches the composite structure I. As shown in Figures 5(a) and 5(b), there is a tensile stress at the interface of $\mathrm{SiC}$ and UHMWPE. Since the wave impedance of $\mathrm{SiC}$ is higher than that of UHMWPE, the stress wave is reflected as a tensile wave at the interface of $\mathrm{SiC}$ and UHMWPE, causing tensile failure of SiC. UHMWPE has low hardness and provides cushioning for $\mathrm{SiC}$. Therefore, $\mathrm{SiC}$ is first broken into pieces on the surface of UHMWPE and then splashed.

Figure 6 shows high-speed photographs and stress diagrams of the composite structure II. SiC in composite structure II is in a bursting state, and the $\mathrm{SiC}$ fragments are smaller than those of the composite structure I. The abovementioned damage mode shows that the damage degree of $\mathrm{SiC}$ in composite structure II is higher than that of $\mathrm{SiC}$ in composite structure I. Figure 6(a) shows that there is a tensile stress at the interface of $\mathrm{SiC}$ and TC4. In addition, the back plate of SiC is TC4 with high hardness, which exerts a strong supporting force on $\mathrm{SiC}$. The above two factors cause the damage degree of $\mathrm{SiC}$ in composite structure II to be higher than that of $\mathrm{SiC}$ in composite structure I.

Figure 7 shows high-speed photographs and stress diagrams of composite structure III. The composite structure III was prepared by adding MR between UHMWPE and TC4 in the composite structure I. As shown in Figure 7, when the stress wave reaches the composite structure III, $\mathrm{SiC}$ and UHMWPE begin to compress MR and it expands laterally. Due to the cushioning effect of UHMWPE and MR, $\mathrm{SiC}$ is not damaged. With further impact, the compression of MR reaches limit and $\mathrm{SiC}$ cracks on the UHMWPE surface. Subsequently, as shown in Figure 7(d), MR rebounds due to its elasticity. Compared with composite structure I, composite structure III has larger $\mathrm{SiC}$ fragments and higher $\mathrm{SiC}$ integrity. Therefore, composite structure III has better impact resistance than composite structure I. The stress and stress fluctuation of composite structure III are relatively small, indicating that MR has good stress attenuation and stress smoothing effects.

Figure 8 shows high-speed photographs and stress diagrams of composite structure IV. The composite structure IV was prepared by adding MR between TC4 and UHMWPE in composite structure II. As shown in Figure 8, when the stress wave reaches the composite structure IV, $\mathrm{SiC}$ and $\mathrm{TC} 4$ begin to compress $\mathrm{MR}$ and it expands laterally. The strong supporting effect of TC4 causes $\mathrm{SiC}$ to fracture. Compared with composite structure II, the good cushioning effect of MR makes the damage degree of $\mathrm{SiC}$ in composite structure IV smaller. Compared with composite structure III, the strong supporting effect of TC4 leads to a higher damage degree of SiC in composite structure IV. Due to the large elastic modulus of TC4, the deformation of TC4 is small when subjected to impact loading, which causes all the deformation concentrated on MR. Therefore, the deformation of MR in composite structure IV is higher than that of MR in composite structure III.

The arrangement of the damage degree of $\mathrm{SiC}$ in the composite structures is II $>$ I $>$ IV $>$ III. The cushioning effect of MR makes the $\mathrm{SiC}$ damage degree of composite structures III and IV smaller than that of composite structures I and II. 

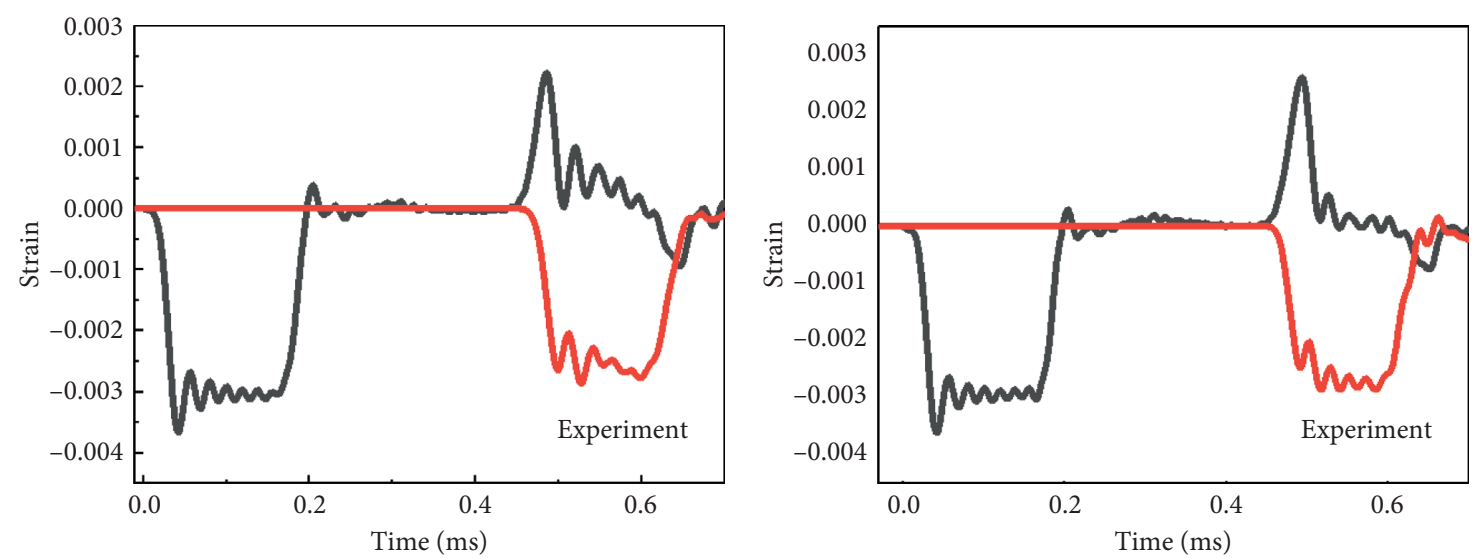

_ Incident and reflected strain

_ Transmitted strain

_ Incident and reflected strain

_ Transmitted strain
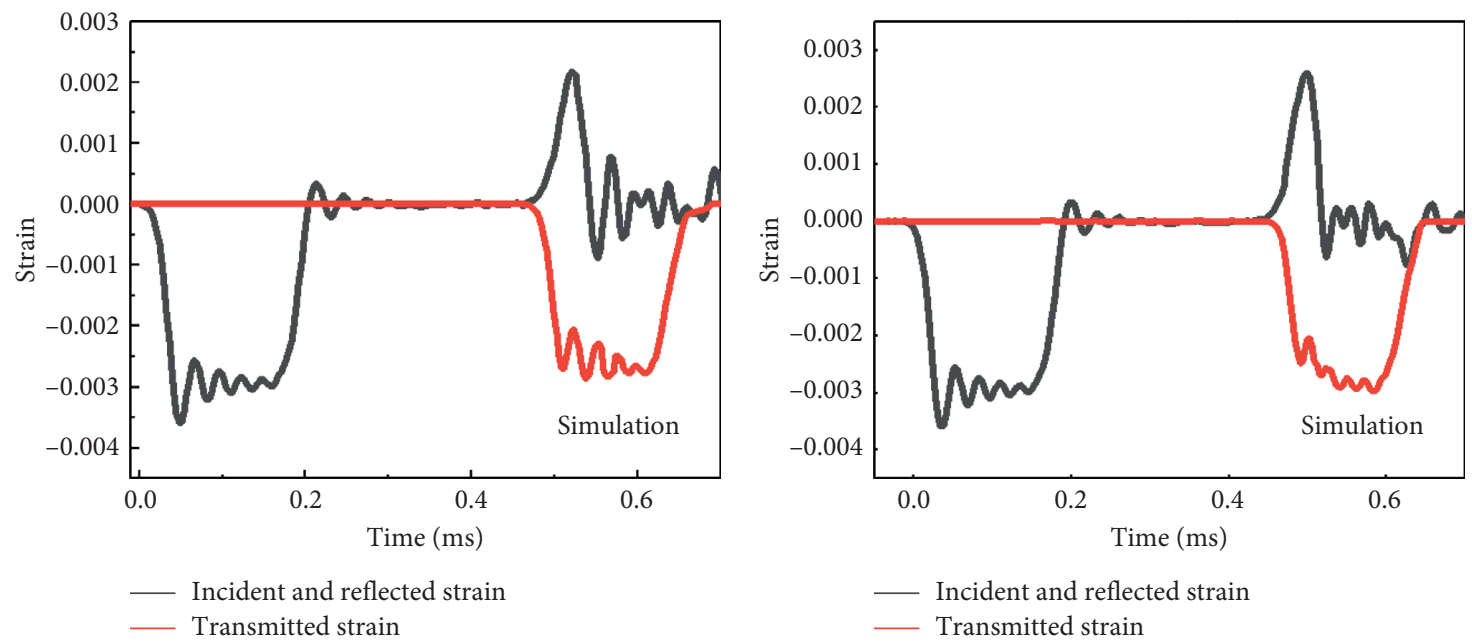

(a)

(b)

Figure 3: Continued. 


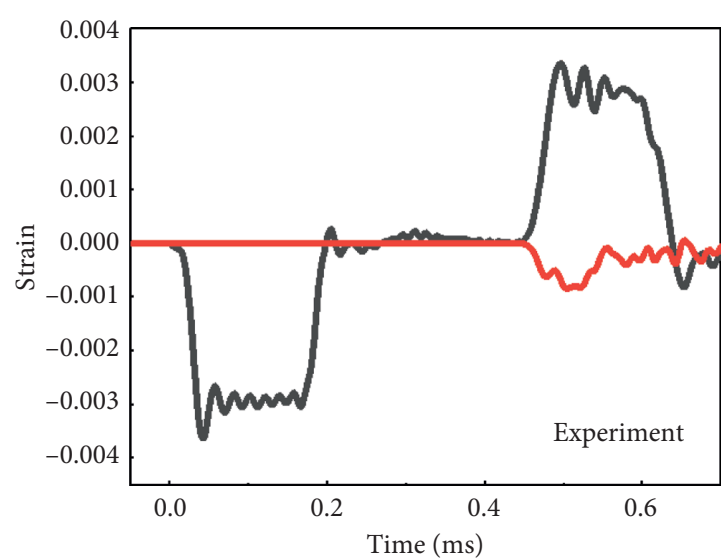

- Incident and reflected strain

__ Transmitted strain

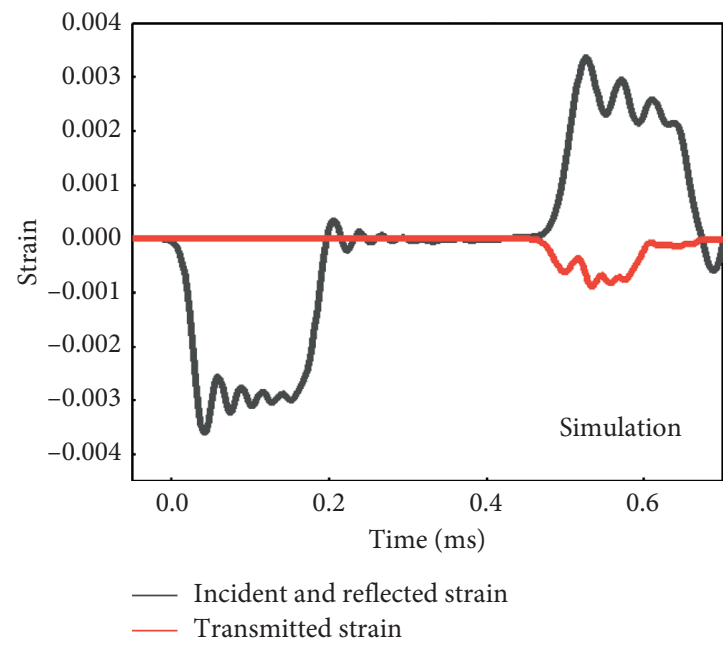

(c)

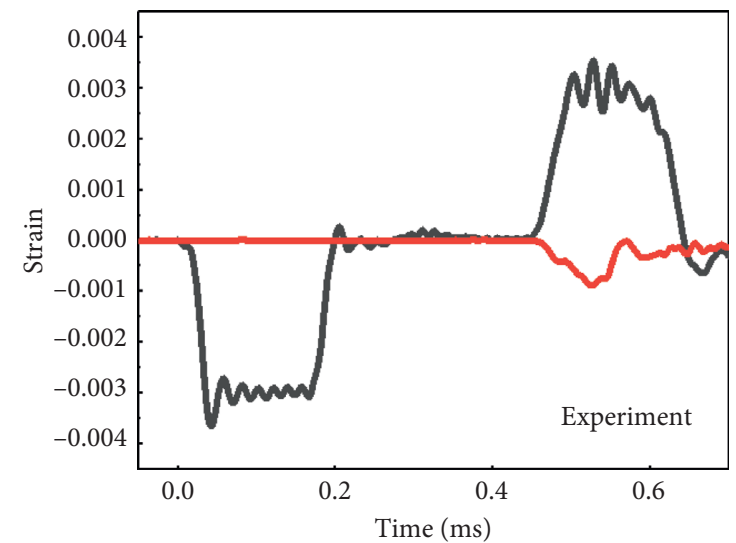

— Incident and reflected strain

_ Transmitted strain

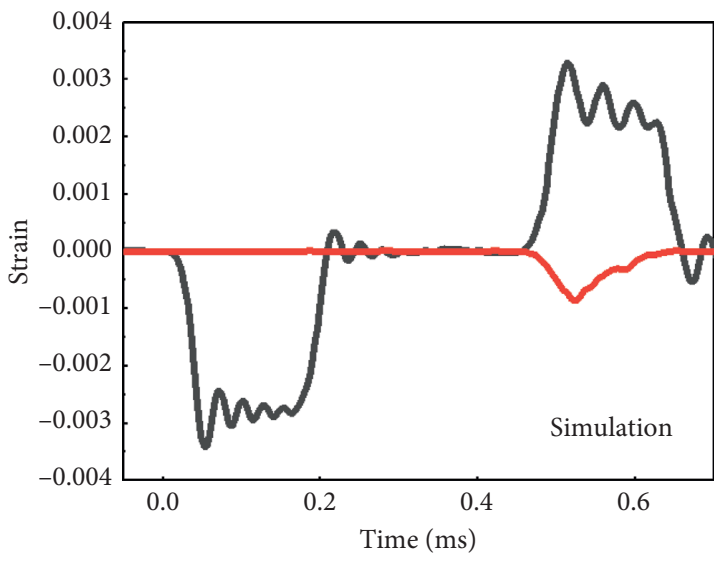

Incident and reflected strain

- Transmitted strain

(d)

Figure 3: Experimental signals and simulation signals: (a) Structure I; (b) Structure II; (c) Structure III; (d) Structure IV.

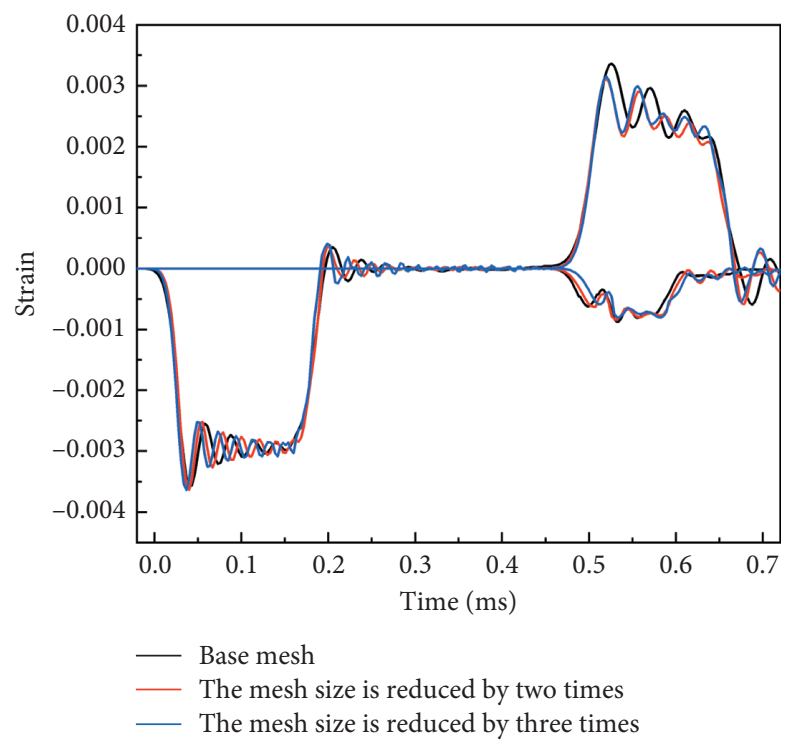

Figure 4: Numerical simulation results with different mesh sizes. 

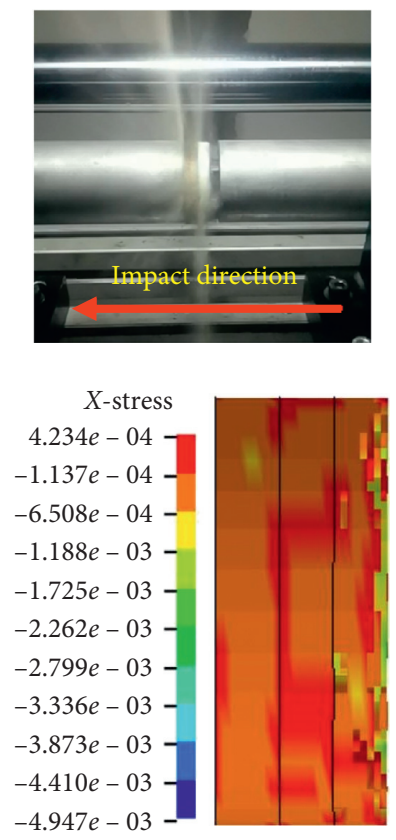

(a)
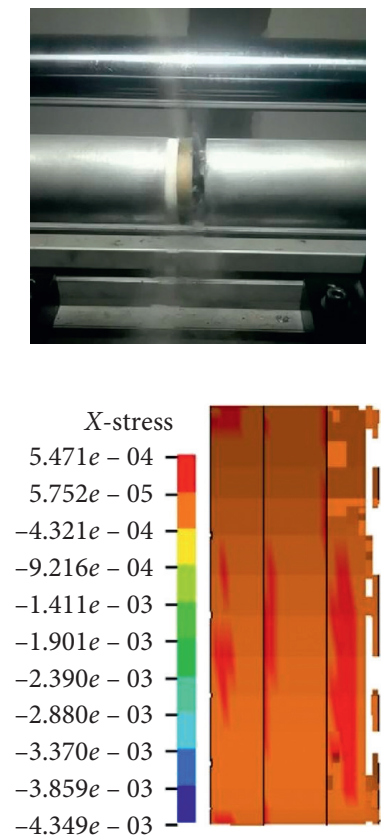

(a)
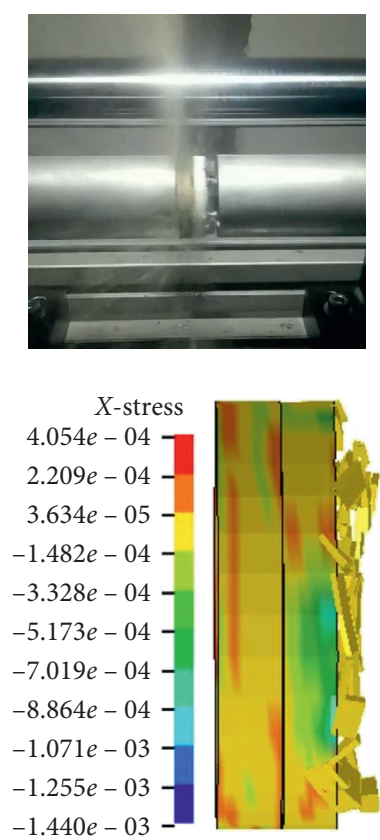

(b)
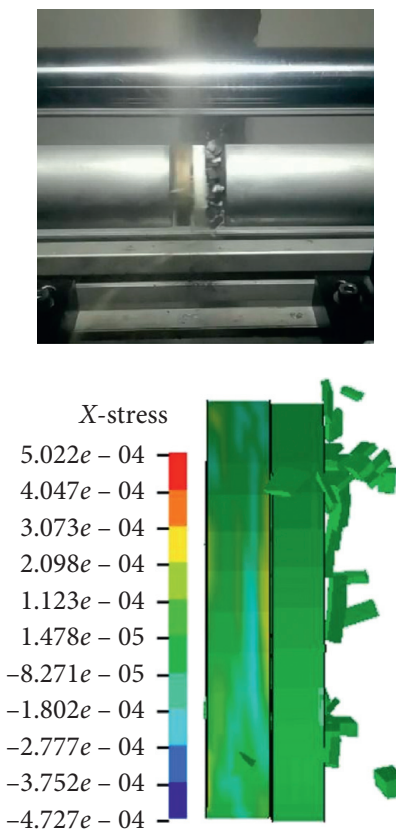

(c)
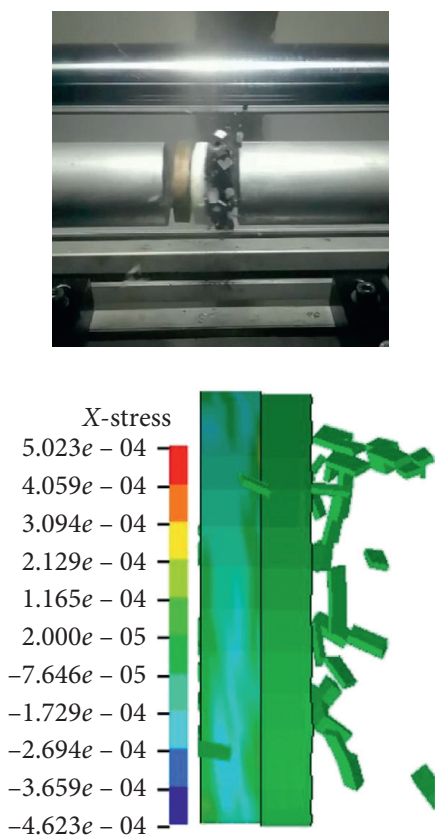

(d)

Figure 5: Structure I SiC/UHMWPE/TC4.
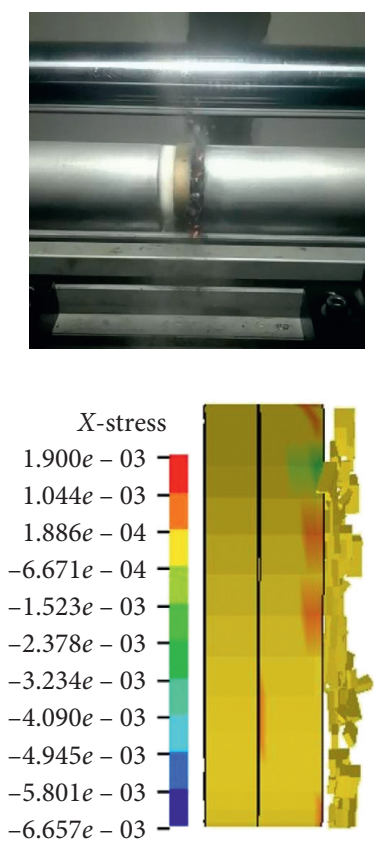

(b)
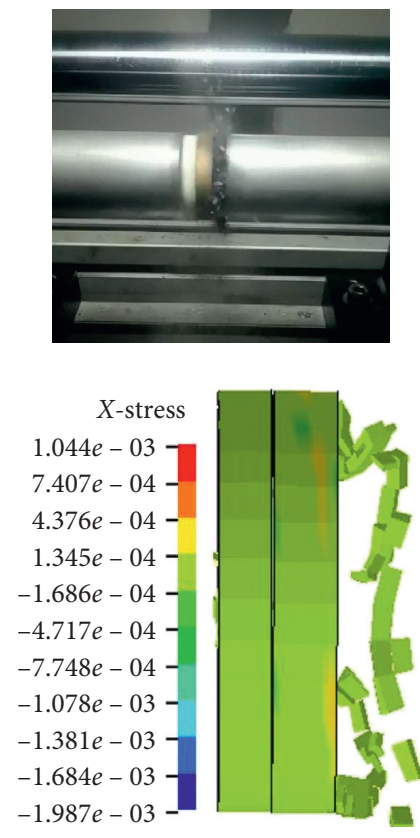

(c)
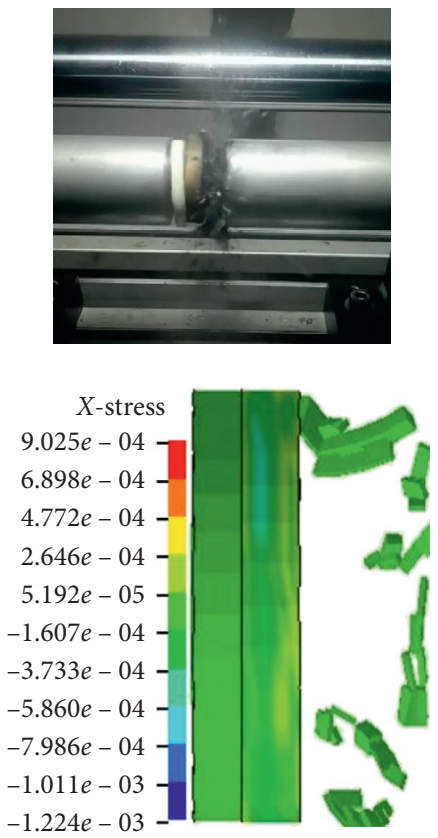

(d)

FIgURE 6: Structure II SiC/TC4/UHMWPE.

In addition, the strong supporting effect of TC4 makes the $\mathrm{SiC}$ damage degree of composite structures II and IV greater than that of composite structures I and III, respectively.

3.3. Stress Wave Propagation Characteristics. As shown in Figure 9, the stress distributions of the composite structures in the process of stress wave propagation were calculated by the finite element method to further study the dynamic response of the composite structures. In the abscissa, $L$ is the total length of the composite structure and $X / L$ represents a certain position on the composite structure $(X / L=0$ indicates the interface between the incident bar and panel; $X / L=1$ indicates the interface between backplane and the transmitted bar). In composite structure I, stress concentration occurs inside $\mathrm{SiC}$, which leads to the generation of crack sources and reduces the 

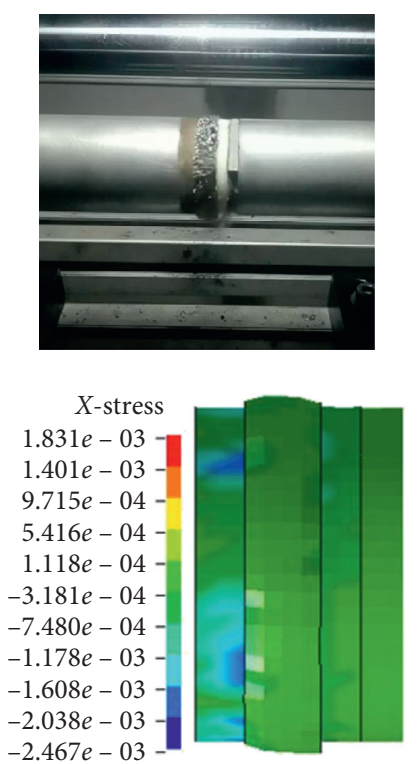

(a)
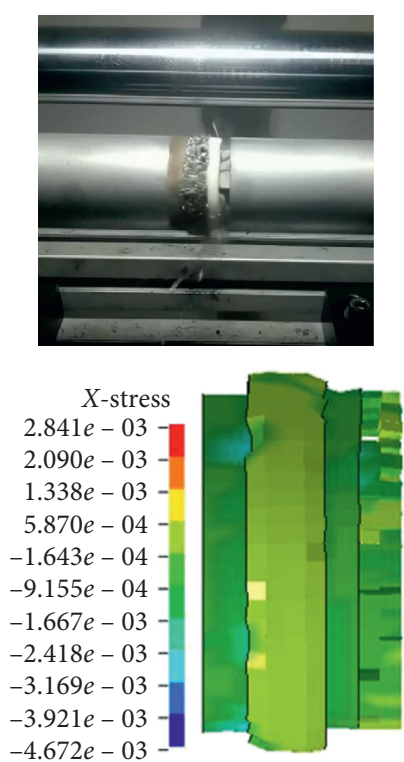

(b)
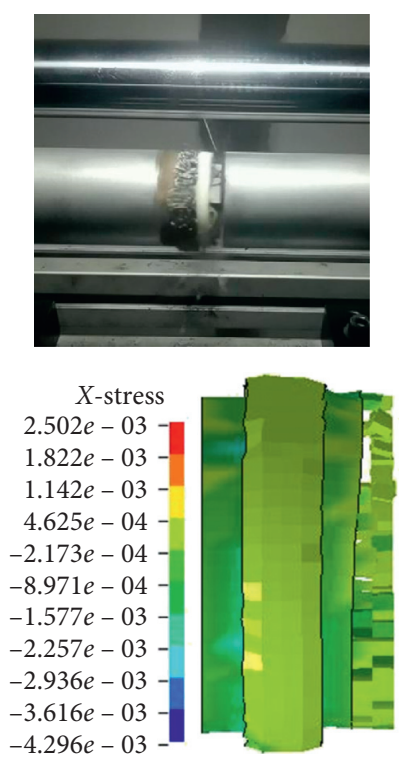

(c)
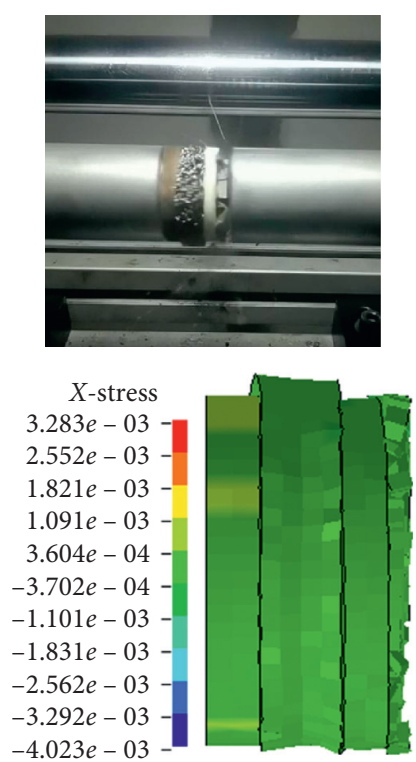

(d)

Figure 7: Structure III SiC/UHMWPE/MR/TC4.
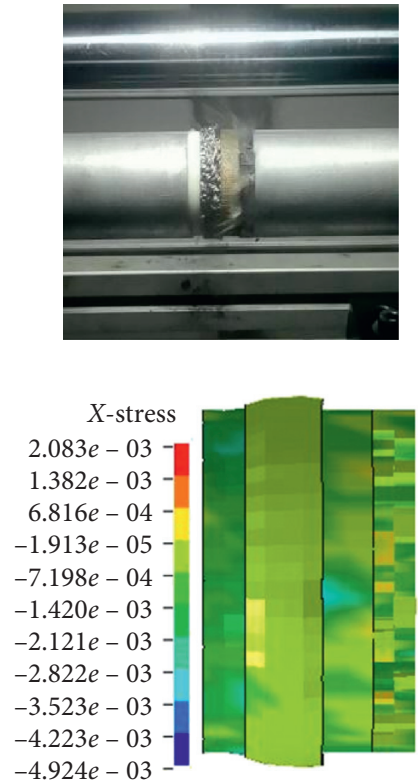

(a)
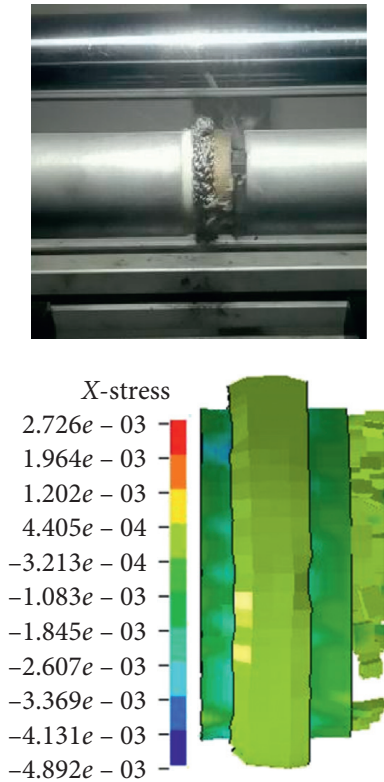

(b)
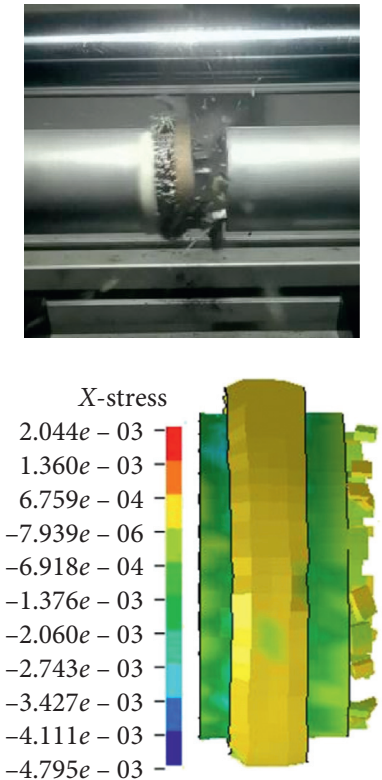

(c)
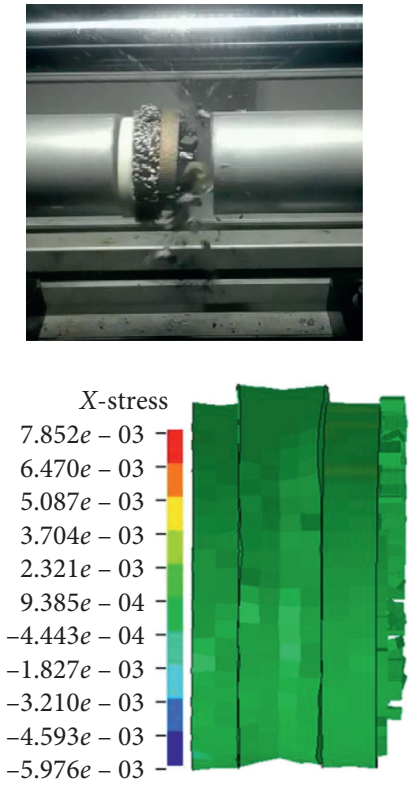

(d)

FIgURE 8: Structure IV SiC/TC4/MR/UHMWPE.

failure strength. Tensile stress appears at the interface of UHMWPE and TC4, which destroys the interface and aggravates the damage of the material. Compared with composite structure I, the stress at the interface in composite structure II is smaller and the stress transition is more gentle. TC4 and UHMWPE in composite structure II have uniform internal stress to avoid material damage caused by stress fluctuation and stress concentration. The stress and stress fluctuation of composite structure III are smaller than those of composite structure I, and the stress transition at the interface is smooth, and there is no tensile stress. Tensile stress appears in $\mathrm{SiC}$ of composite structure IV. MR and UHMWPE in composite structure IV have uniform stress, which avoids the damage caused by stress fluctuations.

Table 5 summarizes the effects of the material arrangement and MR on the dynamic mechanical properties of the composite structures. Comprehensive evaluation of the transmitted waves, failure modes, and stress distributions of four composite structures shows that the composite structure III has the best impact resistance. 


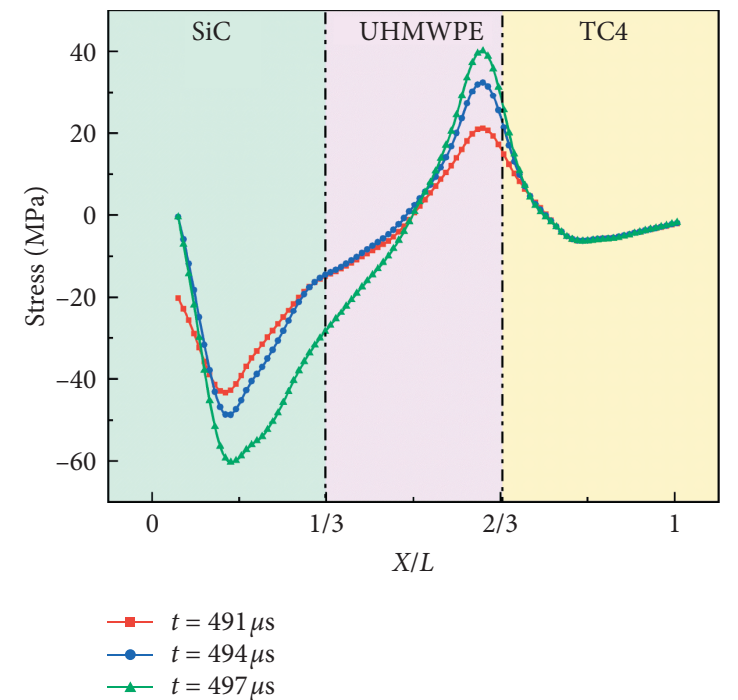

(a)

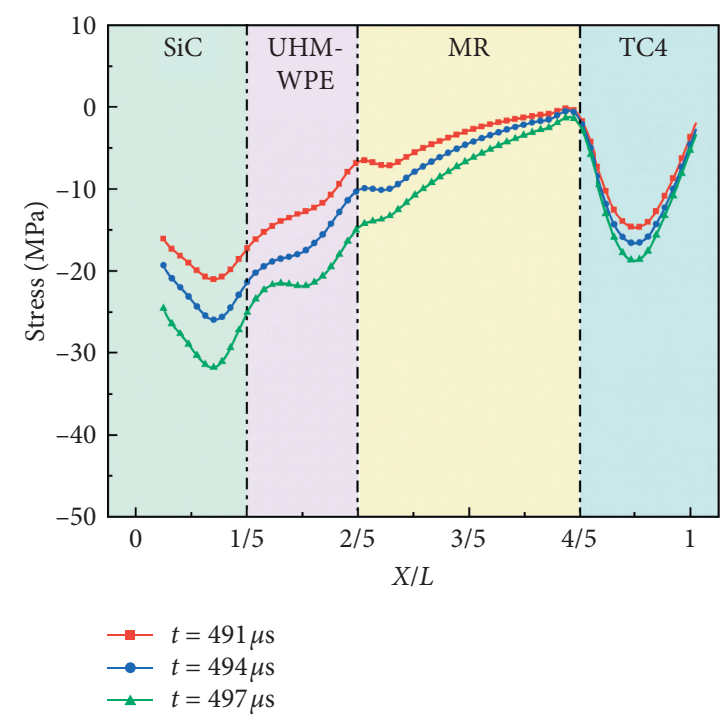

(c)

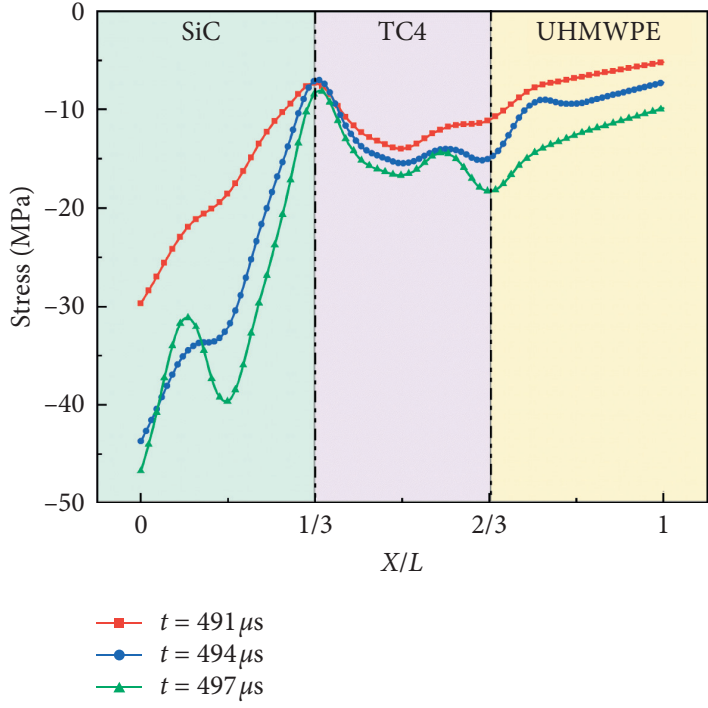

(b)

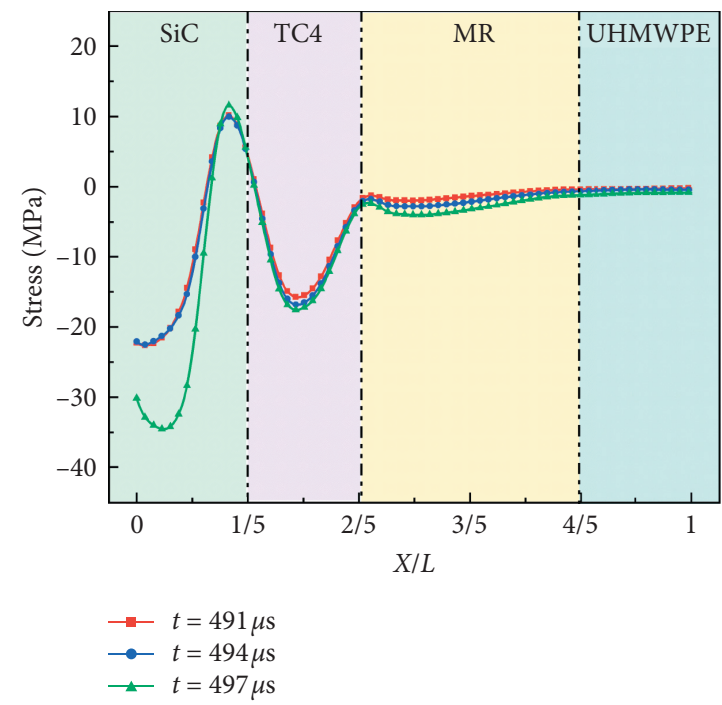

(d)

Figure 9: Stress distribution of structure (a) I; (b) II; (c) III; (d) IV.

TABle 5: Comparison of dynamic mechanical properties.

\begin{tabular}{|c|c|c|c|}
\hline \multirow{4}{*}{$\begin{array}{l}\text { Variable } \\
\\
\text { Material } \\
\text { arrangement }\end{array}$} & \multirow[t]{2}{*}{ Structure } & \multicolumn{2}{|c|}{ Conclusion } \\
\hline & & Structure I & Structure II \\
\hline & I, II & $\begin{array}{l}\text { Low damage of } \mathrm{SiC} \text {; tensile stress at the interface } \\
\text { aggravates the damage of material; the overall stress } \\
\text { of the structure fluctuates sharply. }\end{array}$ & $\begin{array}{l}\text { High damage of SiC; the stress of interface is small and } \\
\text { the transition is gentle; TC4 and UHMWPW have } \\
\text { uniform stress distribution. }\end{array}$ \\
\hline & & Structure III & Structure IV \\
\hline & III, IV & $\begin{array}{l}\text { Low damage of SiC; stress and stress fluctuation are } \\
\text { small. }\end{array}$ & $\begin{array}{c}\text { High damage of } \mathrm{SiC} \text {; tensile stress at the interface; } \\
\text { large deformation of MR. }\end{array}$ \\
\hline MR layer & I, III & \multirow{2}{*}{\multicolumn{2}{|c|}{$\begin{array}{l}\text { After adding MR, the damage degree of } \mathrm{SiC} \text {, stress, and stress fluctuation is significantly reduced, stress } \\
\text { transition at the interface is smooth, and there is no tensile stress. } \\
\text { After adding MR, the stress of MR and UHMWPE is more uniform but tensile stress appears. }\end{array}$}} \\
\hline & II, IV & & \\
\hline
\end{tabular}


3.4. Energy Dissipation Performance. It is of great value to study the energy conversion process for analyzing the energy dissipation performance of composite structures. Based on the law of conservation of energy [24], incident energy $W_{i}$, reflected energy $W_{r}$, transmission energy $W_{t}$, absorption energy $W$, specific energy absorption SEA, and transmittance $W_{a}$ can be expressed as follows:

$$
\begin{aligned}
W_{i} & =\frac{A C}{E} \int_{0}^{T} \sigma_{i}^{2} \mathrm{~d} t \\
& =\operatorname{AEC} \int_{0}^{T} \varepsilon_{i}^{2} \mathrm{~d} t, \\
W_{r} & =\frac{A C}{E} \int_{0}^{T} \sigma_{r}^{2} \mathrm{~d} t \\
& =\mathrm{AEC} \int_{0}^{T} \varepsilon_{r}^{2} \mathrm{~d} t, \\
W_{t} & =\frac{A C}{E} \int_{0}^{T} \sigma_{t}^{2} \mathrm{~d} t \\
& =\mathrm{AEC} \int_{0}^{T} \varepsilon_{t}^{2} \mathrm{~d} t, \\
W & =W_{i}-W_{r}-W_{t}, \\
W_{a} & =\frac{W_{t}}{W}, \\
\text { SEA } & =\frac{W}{M}, \\
W^{2} &
\end{aligned}
$$

where $A, C$, and $E$ are the cross-sectional area, wave velocity, and elastic modulus of the bar, respectively; $\sigma_{i}, \sigma_{r}$, and $\sigma_{t}$ are the incident stress, reflected stress, and transmission stress, respectively; $\varepsilon_{i}, \varepsilon_{r}$, and $\varepsilon_{t}$ are the incident strain, reflected strain, and transmission strain, respectively; $T$ is the loading time; and $M$ is the mass of the sample.

The calculation results are shown in Table 6 . Since the mass and incident energy are different, the specific energy absorption (SEA) of the composite structures should be referred. It can be found that the SEA of composite structures I and II is much greater than that of composite structures III and IV. In the process of impacting the composite structures, the main source of $W$ is destruction of $\mathrm{SiC}$, which shows that composite structures I and II mainly rely on $\mathrm{SiC}$ destruction to dissipate energy.

Transmission energy $W_{t}$, transmittance $W_{a}$, and reflected energy $W_{r}$ are combined to analyze the energy conversion mechanism of composite structures III and IV. The transmission energy $W_{t}$ and transmittance $W_{a}$ of composite structures III and IV are much smaller than those of composite structures I and II, and the reflected energy $W_{r}$ of composite structures III and IV is much greater than that of composite structures I and II. Due to the low wave impedance of MR, most of the incident energy is reflected, which results in lower transmission energy and higher reflected energy. Therefore, composite structures III and IV mainly rely on reflecting most of the incident energy to dissipate energy.
The energy dissipation mechanisms of the four composite structures can be summarized into two categories as follows: (1) composite structures I and II mainly rely on the destruction of $\mathrm{SiC}$ to dissipate energy, which causes severe damage to $\mathrm{SiC}$ and high transmittance; (2) the composite structures III and IV mainly rely on MR to reflect most of the incident energy. The $\mathrm{SiC}$ damage is small, and the transmittance is low. The analysis of the energy conversion and the comparison of the two types of energy dissipation mechanisms further prove the excellent impact resistance of the MR composite structure.

3.5. The Influence of MR Thickness. The influence of MR thickness on the stress wave propagation characteristics and energy dissipation performance of composite structures was discussed. Figure 10 shows the stress distributions of structure III with different MR thicknesses. Since the trends of curves at different times in each structure are the same and the stress distribution of $506 \mu \mathrm{s}$ is the most obvious, the $506 \mu$ s curves are taken as examples to illustrate the influence of the MR thickness on the stress wave distribution. The stress distributions of $\mathrm{SiC}$ in the three structures are (a) $-69 \mathrm{MPa}-20 \mathrm{MPa}$; (b) $-45 \mathrm{MPa}-23 \mathrm{MPa}$; and (c) $-37 \mathrm{MPa}-21 \mathrm{MPa}$. The stress and stress fluctuations of $\mathrm{SiC}$ decrease with the increase in the thickness of MR. The stress distributions of UHMWPE in three structures are (a) $-73 \mathrm{MPa} \sim-45 \mathrm{MPa}$; (b) $-45 \mathrm{MPa} \sim-25 \mathrm{MPa}$; and (c) $-33 \mathrm{MPa}-10 \mathrm{MPa}$. As the thickness of MR increases, the stress and stress fluctuations of UHMWPE decrease. The stress distributions of MR are as follows: (a) the stress of MR decreases first and then remains at $-20 \mathrm{MPa}$; (b) the stress is reduced from $-25 \mathrm{MPa}$ to $-5 \mathrm{MPa}$; and (c) the stress first increases and then decreases $(-5 \mathrm{MPa} \sim-10 \mathrm{MPa} \sim 0 \mathrm{MPa})$. The stress change trends of MR with different thicknesses are different, and the overall stress of MR decreases with the increase in MR thickness. The stress of TC4 all increases first and then decreases. The stress distributions of TC4 are (a) $-25 \mathrm{MPa} \sim-15 \mathrm{MPa}$; (b) $-23 \mathrm{MPa} \sim-5 \mathrm{MPa}$; and (c) $-15 \mathrm{MPa}-5 \mathrm{MPa}$. As the MR thickness increases, the stress and stress fluctuation of TC4 decrease.

The increase in the MR thickness in composite structure III reduces the stress and stress fluctuation of $\mathrm{SiC}$, UHMWPE, and TC4 but does not change their stress trends. The stress change trends of MR with different thicknesses are different, but it can be found that the overall stress of MR decreases with the increase in MR thickness. However, as shown in Figure 10(c), the increase in MR thickness results in stress concentration inside MR.

Figure 11 shows the stress distributions of structure IV with different MR thicknesses. The $506 \mu$ s curves are taken as examples to illustrate the influence of MR thickness on stress wave distribution. In three structures, the stress of $\mathrm{SiC}$ increases first and then decreases. The change trends of $\mathrm{SiC}$ stress are (a) $-5 \mathrm{MPa}-45 \mathrm{MPa} \sim-25 \mathrm{MPa}$; (b) $-32 \mathrm{MPa} \sim$ $-39 \mathrm{MPa} \sim 15 \mathrm{MPa}$; and (c) $-32 \mathrm{MPa} \sim 39 \mathrm{MPa} 2 \mathrm{MPa}$. In Figure 11(a), the stress concentration of $\mathrm{SiC}$ is obvious. When the MR thickness increases to $10 \mathrm{~mm}$, the stress concentration of $\mathrm{SiC}$ is relieved, but tensile stress appears at 
TABLE 6: Energy conversion.

\begin{tabular}{|c|c|c|c|c|c|c|c|}
\hline Structure & $M(\mathrm{~g})$ & $W_{i}(\mathrm{~J})$ & $W_{r}(\mathrm{~J})$ & $W_{t}(\mathrm{~J})$ & $W(\mathrm{~J})$ & SEA (J/g) & $W_{a}$ \\
\hline Structure I & 53.5 & 655.42 & 68.16 & 412.45 & 174.81 & 3.27 & 0.6293 \\
\hline Structure II & 53.5 & 651.28 & 50.65 & 408.48 & 192.15 & 3.59 & 0.6272 \\
\hline Structure III & 83.5 & 702.35 & 523.68 & 17.25 & 161.42 & 1.93 & 0.0246 \\
\hline Structure IV & 83.5 & 695.65 & 511.56 & 18.36 & 165.73 & 1.98 & 0.0264 \\
\hline
\end{tabular}

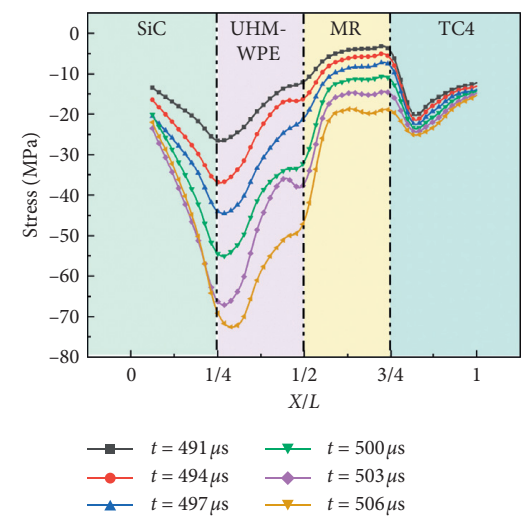

(a)

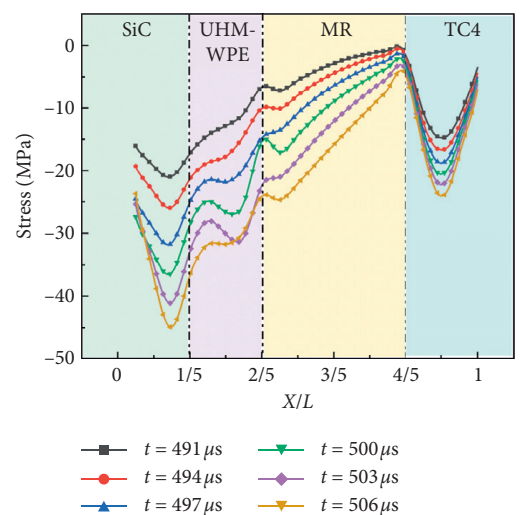

(b)

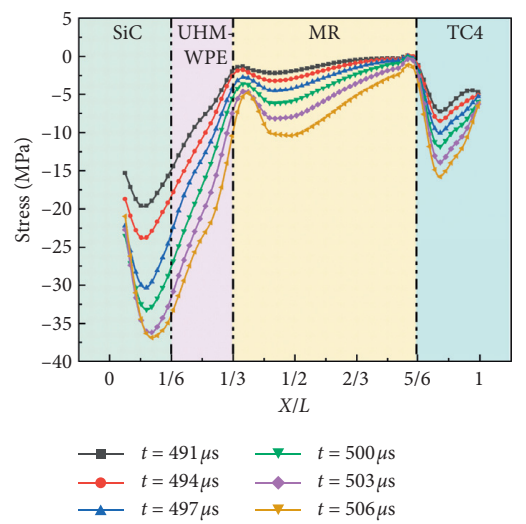

(c)

FIgURe 10: Structure III with different MR thicknesses: (a) $5 \mathrm{~mm} \mathrm{MR;} \mathrm{(b)} 10 \mathrm{~mm} \mathrm{MR}$; (c) $15 \mathrm{~mm} \mathrm{MR.}$

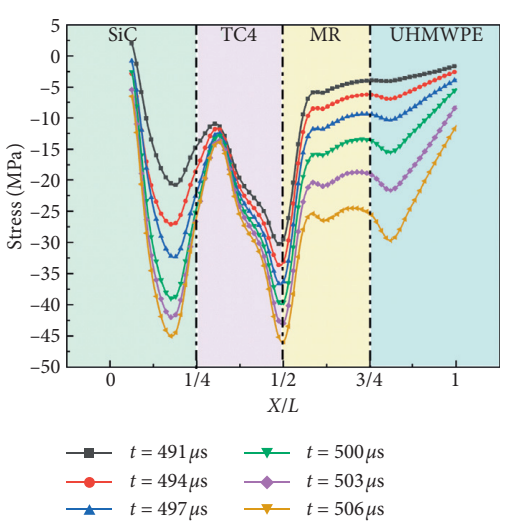

(a)

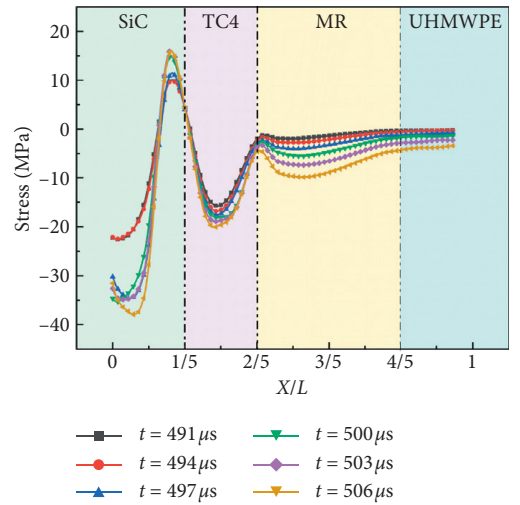

(b)

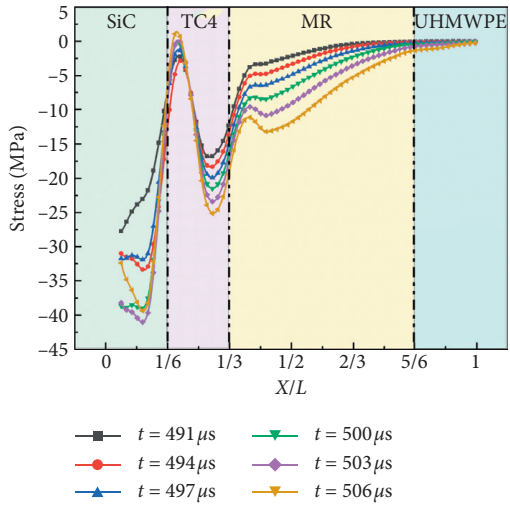

(c)

FIgURE 11: Structure IV with different MR thicknesses: (a) $5 \mathrm{~mm}$ MR; (b) $10 \mathrm{~mm} \mathrm{MR;} \mathrm{(c)} 15 \mathrm{~mm} \mathrm{MR.}$

the interface of $\mathrm{SiC}$ and TC4. When the MR thickness is $15 \mathrm{~mm}$, the tensile stress at the interface of $\mathrm{SiC}$ and TC4 decreases. The stress distributions of TC4 are (a) $-45 \mathrm{MPa} \sim-15 \mathrm{MPa}$; (b) $-20 \mathrm{MPa} 5 \mathrm{MPa}$; and (c) $-25 \mathrm{MPa} 2 \mathrm{MPa}$. The stress fluctuation of TC4 decreases as the thickness of MR increases. The stress change trends of UHMWPE are (a) $-25 \mathrm{MPa}-30 \mathrm{MPa}-10 \mathrm{MPa}$; (b) $-5 \mathrm{MPa}$; and (c) $0 \mathrm{MPa}$. As MR thickness increases, UHMWPE stress is reduced and more uniform. The stress of MR in three structures all remains uniform after fluctuating: (a) the stress of MR is maintained at $-25 \mathrm{MPa}$ after fluctuating; (b) the stress of $\mathrm{MR}$ is maintained at $-5 \mathrm{MPa}$ after fluctuating; and (c) the stress of MR is maintained at $0 \mathrm{MPa}$ after fluctuating. As the MR thickness increases, the stress of MR decreases.
As the thickness of MR increases, the stress of TC4, UHMWPE, and MR decreases. However, as shown in Figure 11(b), when the thickness of MR increases to $10 \mathrm{~mm}$, tensile stress appears at the interface between SiC and TC4, which aggravates the damage of the material. In addition, as shown in Figures 11(b) and 11(c), stress concentration also occurs in MR.

Table 7 shows the energy conversion of the composite structures with different thicknesses of MR. As the thickness of MR increases, the reflected energy increases and the transmitted energy decreases, which indicates that the effect of the energy dissipation of MR composite structure increases as the MR thickness increases. Under the condition of the same MR thickness, the transmittance of the composite structure III is lower than that of the composite 
TABLE 7: Energy conversion.

\begin{tabular}{cccccccccc}
\hline & Speed $(\mathrm{m} / \mathrm{s})$ & $M(\mathrm{~g})$ & Height of MR $(\mathrm{mm})$ & $W_{i}(\mathrm{~J})$ & $W_{r}(\mathrm{~J})$ & $W_{t}(\mathrm{~J})$ & $W(\mathrm{~J})$ & SEA $(\mathrm{J} / \mathrm{g})$ & $W_{a}(\mathrm{~J})$ \\
\hline \multirow{3}{*}{ Structure III } & \multirow{3}{*}{30} & 68.5 & 5 & 10 & 700.74 & 519.92 & 20.04 & 160.78 & 2.35 \\
& & 83.5 & 15 & 702.35 & 523.68 & 17.25 & 161.42 & 1.93 & 0.0286 \\
& & 98.5 & 5 & 711.00 & 536.17 & 11.66 & 163.17 & 1.66 & 0.0164 \\
\hline \multirow{3}{*}{ Structure IV } & \multirow{2}{*}{30} & 68.5 & 10 & 697.57 & 491.29 & 42.50 & 163.78 & 2.39 & 0.0609 \\
& & 83.5 & 15 & 695.65 & 511.56 & 18.36 & 165.73 & 1.98 & 0.0264 \\
& & 98.5 & 699.87 & 530 & 13.84 & 156.03 & 1.58 & 0.0198 \\
\hline
\end{tabular}

structure IV, which further proves that the impact resistance of composite structure III is better than that of composite structure IV.

\section{Conclusion}

Four composite structures desinged were taken as the research object, and the SHPB tests were carried out. The finite element models of SHPB tests were established, and the correctness was verified. Through experiments and simulations, the influences of material arrangement and MR on the transmitted waves, damage forms, stress wave propagations, and energy dissipations of the composite structures were analyzed. Finally, the stress wave propagation and energy dissipation of the composite structures III and IV with different MR thicknesses were studied. The main conclusions are as follows:

(1) MR can effectively delay the stress wave and greatly attenuate the transmission energy. The experimental results show that the damage degree of $\mathrm{SiC}$ is greatly affected by the material on its back and is positively correlated with the stress and stress fluctuations of $\mathrm{SiC}$. The arrangement of the damage degree of $\mathrm{SiC}$ is II $>$ I $>$ IV $>$ III, which is consistent with the simulation results. The damage of $\mathrm{SiC}$ in composite structures III and IV is significantly lower than that in composite structures I and II, indicating that MR effectively reduces the stress of $\mathrm{SiC}$ and successfully suppresses the overall stress fluctuation of the composite structures by interfering with the transmission of stress waves. It is found that the $\mathrm{SiC}$ damage of composite structure III is lower than that of composite structure IV through further comparison. It can be preliminarily confirmed that UHMWPE should be used as the back plate of SiC to give full play to the cushioning effects of UHMWPE and MR, and TC4 as the back plate of $\mathrm{SiC}$ cannot exert the maximum cushioning effect. The $\mathrm{SiC}$ damage of composite structure I is lower than that of composite structure II, which can also prove this conclusion.

(2) MR in composite structure can attenuate and smooth the stress wave. Different material arrangements significantly affect the propagation of stress wave. A comprehensive comparison of transmitted waves, damage forms, stress wave propagations, and energy dissipations of the four composite structures shows that structure III has the best impact resistance.
(3) The energy dissipation mechanisms of the four composite structures can be summarized into two categories. The composite structures I and II dissipate energy mainly through the damage of $\mathrm{SiC}$, resulting in severe damage to $\mathrm{SiC}$ and high transmittance. The composite structures III and IV reflect a large amount of energy, and the damage degree of $\mathrm{SiC}$ and transmittance is low. Therefore, the energy dissipation performance of the MR composite structure is better, and the energy dissipation mechanism is more reasonable.

(4) As the thickness of MR increases, the stress of the composite structure is reduced and smoothed and the transmittance is significantly reduced. However, it can also cause stress concentration and interface tensile stress. Therefore, it is necessary to balance the advantages and disadvantages of increasing the thickness of MR. When the thicknesses of MR are the same, the transmittance of composite structure III is lower than that of composite structure IV, which further proves that composite structure III has better impact resistance.

\section{Data Availability}

The data used to support the findings of this study have not been made available because the data also form part of an ongoing study.

\section{Conflicts of Interest}

The authors declare that there are no conflicts of interest regarding the publication of this paper.

\section{References}

[1] N. Zhou, J. Wang, D. Jiang, K. Tang, and Y. Fang, "Study on the failure mode of a sandwich composite structure under the combined actions of explosion shock wave and fragments," Materials \& Design, vol. 196, Article ID 109166, 2020.

[2] X. Huo, H. Liu, Q. Luo, G. Sun, and Q. Li, "On low-velocity impact response of foam-core sandwich panels," International Journal of Mechanical Sciences, vol. 181, p. 105681, 2020.

[3] A. C. Pereira, F. S. D. Assis, F. D. C. G. Filho et al., "Ballistic performance of multilayered armor with intermediate polyester composite reinforced with fique natural fabric and fibers," Journal of Materials Research and Technology, vol. 8, no. 5, pp. 4221-4226, 2019.

[4] R. A. Ash, "Vehicle armor," in Lightweight Ballistic Composites, A. Bhatnagar, Ed., pp. 285-309, Woodhead Publishing, Sawston, UK, 2nd edition, 2016. 
[5] X. Yang, J. Ma, D. Wen, and J. Yang, "Crashworthy design and energy absorption mechanisms for helicopter structures: a systematic literature review," Progress in Aerospace Sciences, vol. 114, Article ID 100618, 2020.

[6] Y.-H. Shin, J.-H. Chung, and J.-H. Kim, “Test and estimation of ballistic armor performance for recent naval ship structural materials," International Journal of Naval Architecture and Ocean Engineering, vol. 10, no. 6, pp. 762-781, 2018.

[7] P. Rawat, D. Zhu, M. Z. Rahman, and F. Barthelat, "Structural and mechanical properties of fish scales for the bio-inspired design of flexible body armors: a review," Acta Biomaterialia, vol. 121, 2020.

[8] J. Li, T. Ma, C. Huang et al., "Protective mechanism of helmet under far-field shock wave," International Journal of Impact Engineering, vol. 143, Article ID 103617, 2020.

[9] S. S. Godara and S. Narayan Nagar, "Analysis of frontal bumper beam of automobile vehicle by using carbon fiber composite material," Materials Today: Proceedings, vol. 26, pp. 2601-2607, 2020.

[10] W. G. Davids, J. K. Botting, and M. Peterson, "Development and structural testing of a composite-reinforced timber highway guardrail," Construction and Building Materials, vol. 20, no. 9, pp. 733-743, 2006.

[11] A. Rajaneesh, I. Sridhar, and S. Rajendran, "Impact modeling of foam cored sandwich plates with ductile or brittle faceplates," Composite Structures, vol. 94, no. 5, pp. 1745-1754, 2012.

[12] H. Liu, Z. K. Cao, G. C. Yao, H. J. Luo, and G. Y. Zu, "Performance of aluminum foam-steel panel sandwich composites subjected to blast loading," Materials \& Design, vol. 47, pp. 483-488, 2013.

[13] M. Garcia-Avila, M. Portanova, and A. Rabiei, "Ballistic performance of composite metal foams," Composite Structures, vol. 125, pp. 202-211, 2015.

[14] S. Cai, J. Liu, P. Zhang, C. Li, Y. Cheng, and C. Chen, "Experimental study on failure mechanisms of sandwich panels with multi-layered aluminum foam/UHMWPE laminate core under combined blast and fragments loading," Thin-Walled Structures, vol. 159, Article ID 107227, 2021.

[15] Y.-J. Wang, Z.-J. Zhang, X.-M. Xue, and L. Zhang, "Experimental investigation on enhanced mechanical and damping performance of corrugated structure with metal rubber," Thin-Walled Structures, vol. 154, Article ID 106816, 2020.

[16] L. Ping, Q. Tan, L. Wu, and H. Guo, "Compressive and pseudo-elastic hysteresis behavior of entangled titanium wire materials," Materials Science and Engineering A, vol. 527, pp. 3301-3309, 2010.

[17] Y. Ma, D. Gao, D. Zhang, and J. Hong, "Compressive and dissipative behavior of metal rubber under constraints," Physica Status Solidi (b), vol. 252, 2015.

[18] J. Hong-Yuan, X. Yu-Hong, A. O. Hong-Rui, D. Chun-Fang, and A. M. Ulanov, "Lifetime of metal rubber isolator with different vibration amplitudes," Journal of Central South University, vol. 12, pp. 181-185, 2005.

[19] H. Gao, C. Xiong, J. Yin, and H. Deng, "Study on antipenetration performance of porous metal sandwich composite structures," Science of Advanced Materials, vol. 11, pp. 708-721, 2019.

[20] J. P. Noël, L. Renson, C. Grappasonni, and G. Kerschen, Dynamic Behavior of Materials, Wiley, Hoboken, NJ, USA, 2016.

[21] Y. Li, Y. Guo, H. Hu, and Q. Wei, “A critical assessment of high-temperature dynamic mechanical testing of metals,"
International Journal of Impact Engineering, vol. 36, no. 2, pp. 177-184, 2009.

[22] C. Tian, X. An, Q. Sun, and Y. Dong, "Experimental and numerical analyses of the penetration resistance of ceramicmetal hybrid structures," Composite Structures, vol. 211, pp. 264-272, 2019.

[23] L. Wang, T. Tang, and J. Ma, "Numerical simulation of UHMWPE laminated fiber plate resisted projectile," Applied Mechanics and Materials, vol. 395-396, pp. 24-28, 2013.

[24] H. Gao, C. Xiong, J. Yin, and H. Deng, "Research on dynamic accumulation effect and constitutive model of aluminum foams under dynamic," Impact International Journal of Metalcasting, vol. 13, 2018. 